\title{
Spectral Recognition Techniques and MLC of IRS P6 LISS III image for Coastal Landforms Extraction along South West Coast of Tamilnadu, India
}

\author{
S. Kaliraj and N. Chandrasekar
}

\begin{abstract}
The Remote sensing technology is measured or observed reflected energy to construct an image of the landscape beneath the platform passage in a discrete pixel format. The geometric and radiometric characteristics of remotely sensed image provide information about earth's surface. In the present study, the primary data product obtained from IRS P6 satellite LISS - III images $(23.5 \mathrm{~m})$ are used to extract the landforms the South West coast of Tamil nadu, India. The study area comprises different types of landforms in nature. The selected image processing techniques are employed such as, geometric correction, radiometric correction for removal of atmospheric errors and noise from image and to identify spectral and spatial variations in structure, texture, pattern of objects in the image. Here, the spectral recognition statistics namely edge detection; edge enhancement; histogram equalization, principal component analysis and maximum likelihood classifier algorithms are applied for demarcate the coastal landforms. In the maximum likelihood classification process, the spectral properties (Digital Number) of an object $\left(k_{n}\right)$ in the image has been identified using mean and covariance of pixels in training set, then the probability function $\left(P_{x}\right)$ determines the distribution of that group of pixels (class) in the image. The coastal landforms are segmented as separate class from the image based on their spectral and spatial characteristics such as shoreline, beach, sand dunes, erosional and accretion lands, water body, river deltas, and manmade infrastructure with attribute of shape, area, location and spatial distribution.
\end{abstract}

Keywords--- Remote Sensing, Spectral Pattern Recognition, Maximum Likelihood Classifier, IRS P6 - ISS III Image, Coastal Landforms India

\section{INTRODUCTION}

A RECENT space technology namely remote sensing and GIS is an effective and empirical tool to predict the land

S. Kaliraj, Research Scholar (DST-INSPIRE Fellow), Centre for GeoTechnology, Manonmaniam Sundaranar University, Tirunelveli. Email:thayakaliraj@gmail.com.

N. Chandrasekar, Professor \& Head, Centre for GeoTechnology, Manonmaniam Sundaranar University, Tirunelveli, India.

DOI: $10.9756 /$ BIJAIP.10028 use and land cover features of the earth surface from the satellite image [1]. The scientific study of landforms and its location, distribution, dynamic processes using remote sensing and GIS leads to manage the natural resources and this is the national perspective for social and economic development. The features of the earth surface were delineated from satellite images using digital classification algorithm integrated with the computer-based program was produced virtual results [2]. Remote sensing is the aforementioned data collection technology to observe the earth surface by the sensor mounted on spacecraft (satellite) without direct physical contact [3]. The observation of reflected EMR is a valuable source to distinguish the objects on the earth surface from the satellite image [4].

Remotely sensed image analysis concentrate primary properties of pixels such as spectral, spatial, temporal and radiometric resolution, which are determined by the optical sensor. These characteristics have the important role to distinguish objects spatially near or spectrally similar feature [5]. Satellite data provides baseline information of seashore line variation, geomorphology, and land-use. GIS is used to collect, store, retrieve and analysis the spatial and non-spatial data collected from various sources to provide result with more reliability [6].

Remote sensing technology provides satellite image with synaptic coverage on large area and high spatial resolution to identify individual species in biodiversity and delineating various forest types at national, regional and local level, and that facilitates manage and conserving the forest biodiversity worldwide [7]. Computer based image processing or signal processing merely involved to enhance the image or picture, but the algorithm correlated with the geographic information systems that can be represent the earth or real world features and extract the land form features from the image that may be sources of various planning and management of human sophisticated life [8]. Maximum likelihood classifier algorithm is applied to classify the group of pixels into different class with respect to the mean cluster of training sets; in which, the mean of pixel values labeled not only by checking its Euclidean distance to the class centers but also looking at the shape, size, and orientation of the similar pixels in the feature space [9].

The statistical algorithm executed using image-processing software for image enhancement and classification of satellite 
image to extract the features. In their study, the classifications were conducted by separating the images into urban and rural pieces, because accurate classification within, and around urban areas were difficult. Some zones in urban pieces with unknown classes were further separated into sub pieces to determine the classes in the micro scale [10]. A maximum likelihood-based approach is used to reduce noise and clear segmentation of synthetic aperture radar (SAR) images [11].

This study has been attempted to delineate the coastal land features using the number of digital image processing techniques and classification algorithm from IRS-P6 LISS III images. GIS functionalities were applied for mapping of the extracted features.

\section{STUDY AREA}

The IRS P6 - LISS III satellite image (product number: 117012900101, Path 101; Row 068) with 23.5 meter spatial resolution was covered the area of South-West coast of Kanyakumari district in Tamil nadu. India has been used for the study. The image was acquired on January 23, 2010 provided by NRSC, Hyderabad. The study area geographical extent is $77^{\circ} 16^{\prime} 36.29^{\prime}$ ' $\mathrm{E}$ to $77^{\circ} 34^{\prime} 27.08^{\prime}$ ' $\mathrm{E}$ longitude and $8^{\circ}$ $03^{\prime} 22.45^{\prime \prime}$ to $22.45^{\prime}{ }^{\prime} \mathrm{N}$ to $8^{\circ} 10^{\prime} 14.45^{\prime}{ }^{\prime} \mathrm{N}$ latitude. The total length of the coastal line is $42.59 \mathrm{Km}$, and the area is 19.44 Sq.km. Mean Sea Level (MSL) of the area is from $0.2 \mathrm{~m}$ to $4.15 \mathrm{~m}$ above the $0 \mathrm{~m}$ depth Chart Datum (CD). The local mean tidal level is $0.5 \mathrm{~m}$, and the high tidal level is $1.60 \mathrm{~m}$ $\mathrm{CD}$. The landforms of this coastal area are very into nature such as shoreline, erosional and accretion landforms, sand dunes, beaches, vegetative cover, shallow lands, settlements and manmade infrastructure. The semi dendritic drainage pattern is common in the drainage system of the area. Elevation of the area is from $9 \mathrm{~m}$ to $39 \mathrm{~m}$ across the onshore to the aggrandizement of steep sand dune batches and bathymetric level from 1 to 10 fathoms $(18 \mathrm{~m})$ in onshore. The study area experiences moderate subtropical climate with an annual average rainfall is $14.65 \mathrm{~cm}$ and temperature ranges from $24 \mathrm{oC}$ to $26 \mathrm{o} \mathrm{C}$. The population of this area is $17.2 \%$ of total population in the district (Fig. 1).

\section{MATERIALS AND METHODS}

Remotely sensed image is the digital representations of the Earth surface. The image is composed by pixel or picture elements in row and column format, and they are comprised with Digital Number values (DN value) to represent the distinct features of the earth surface. The DN values are assigned to that pixel are the records of reflected radiation from the Earth's surface. The spectral and spatial properties of the objects define by DN value (spectral bands or channels) of the specific pixels of the image. The extraction of landforms from the image with the ground reality was done by image enhancement techniques and classification methods, such as edge detection, edge enhancement, histogram equalization and principal component analysis and the maximum likelihood classifier algorithm applied to delineate the feature classes based on the spectral signature of training sets. In the study, IRS P6 LISS III - FCC image with 23.5 meter resolution is digitally processed and interpreted by using digital image processing techniques and classification methods to extract landform features. In general, the most widely used data composition format for information extraction is the False Color Composite (FCC) image, which means the spectral bands arrangement is replaced from Green to Blue, Red to Green and Infrared to Red because of poor reflection in Blue

\begin{tabular}{|l|l|}
\hline Name of the Satellite & IRS P6 (Resourcesat) \\
Sensor & LISS III \\
Date of Acquisition & 23-JAN-10 \\
Scan Lines & 2967 \\
Pixels & 2955 \\
Bytes Per Pixel & 1 \\
Image Record Length(Bytes) & 2987 \\
Spectral resolution( $\mu \mathrm{m})$ & 4 bands \\
Band 2 & \\
Band 3 & 0.52 to 0.59 - Green \\
Band 4 & 0.62 to 0.68 - Red \\
Band 5 & 0.77 to 0.86 - Near IR \\
Spatial resolution & 1.55 to $1.70-$ SW IR \\
& $23 \times 23 \mathrm{~m}$ \\
\hline
\end{tabular}
region.

Table I. IRS P6 - LISS III Image Specification

\section{A. Geometric Correction and Registration}

The image is recorded by sensors onboard on satellite contain errors in geometry and in the measured brightness values (radiometry) of the pixels due to elative motion of satellite in its orbit, curvature of the -earth surface, and mechanism malfunction. The geometric error in IPS P6 LISS III image corrected by the process of geo-reference by inputting number of ground coordinates with UTM- WGS 84 projection and coordinate system. The mathematical relationships between GPS observed Ground Control Points (GCPs) and pixel coordinates of image are substituted into affine transformation and replaced by ground coordinate to represent real world. Above the relationship is used to correct the image geometry distortion using the polynomial equation (affine transformation) that is expressed as,

$$
\begin{aligned}
& \mathrm{u}=\mathrm{a}_{0}+\mathrm{a}_{1 \mathrm{x}}+\mathrm{a}_{2 \mathrm{y}}+\mathrm{a}_{3 \mathrm{xy}}+\mathrm{a}_{4 \mathrm{x}}{ }^{2}+\mathrm{a}_{5 \mathrm{y}}{ }^{2} \\
& \mathrm{v}=\mathrm{b}_{0}+\mathrm{b}_{1 \mathrm{x}}+\mathrm{b}_{2 \mathrm{y}}+\mathrm{b}_{3 \mathrm{xy}}+\mathrm{b}_{4 \mathrm{x}}{ }^{2}+\mathrm{b}_{5 \mathrm{y}}{ }^{2}
\end{aligned}
$$

Where, $\mathrm{u}, \mathrm{v}$ are the image coordinates (pixel coordinates), $\mathrm{x}, \mathrm{y}$ are the coordinates of the GPS observed GCPs from the study area locations such as road intersections, farm boundaries and fence corners. The $a_{0}, a_{1 x} . a_{5 y}{ }^{2}$ and $b_{0}, b_{1 x} . b_{5 y}{ }^{2}$ are the coeffient of polynomial equation that could used to replace the GCPs to its corresponding pixel coordinates of an image, then the newly assigned coordinates of the pixel in an image interpolated to nearest part consequently using nearest neighbour resembling method for transferring the appropriate GCPs to corresponding pixels of entire image to produce geometrically corrected image. 


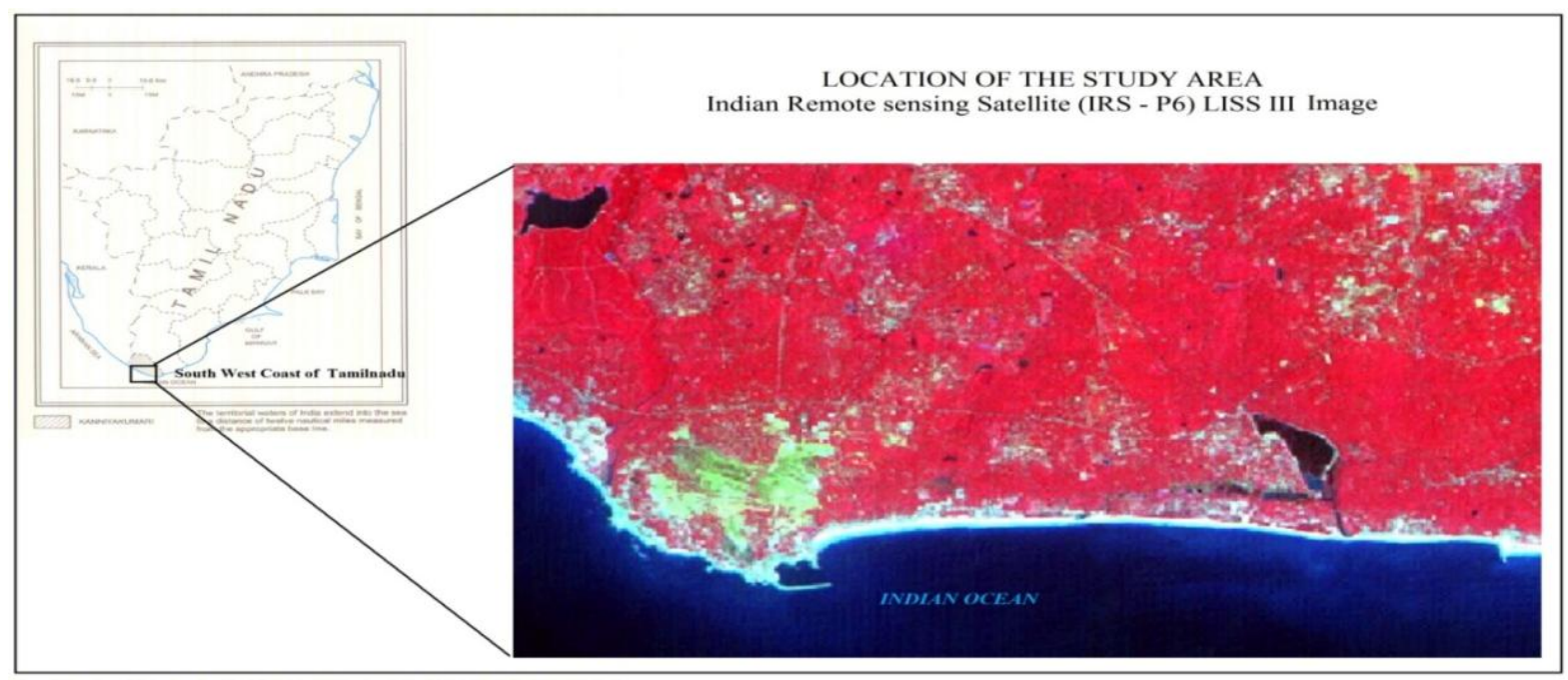

Figure 1: Location of the Study area in IRS P6-LISS III Image

\section{B. Edge Detection and Enhancement}

The edge detection and enhancement are the effective process for improve the geometric details of the image. Here, the IRS P6-LISS III image applied to linear edge enhancement technique to delineate the feature's edges and thereby the shapes of the objects are demarcated by sharpening the brightness value of pixel between two adjacent objects using the formula is expressed as,

$$
\begin{aligned}
& \mathrm{BV}_{\mathrm{i}, \mathrm{j}}=\mathrm{BV} \mathrm{BV}_{\mathrm{i}-1, \mathrm{j}} \\
& B V_{i, j}=B V_{i, j}-B V_{i, j+1} \\
& \mathrm{BV}_{\mathrm{i}, \mathrm{j}}=\mathrm{BV}_{\mathrm{i}, \mathrm{j}}-\mathrm{BV}_{\mathrm{i}+1, \mathrm{j}+1}
\end{aligned}
$$

Where, BV is brightness value of the pixel $(i, j)$ in the image. In this technique, the algorithm is substituted pixels with mid-gray value (DN value: 127 ) in the kernel window (3 x 3 ) as the class with no change, and the pixels contain darkgray tone (less than DN value: 30 ) are reassigned for the pixel with negative difference, then the pixels with light-gray tone (above DN value: 200) is substituted for class of pixels with positive difference. Hence, the transition of BV of pixels from light to dark produces white line, and dark to light produce black lines surrounding the edge of all objects in the image [12]. The edge detection algorithm is performed to detect an edge of the objects from the neighbour objects to increase contrast close to an edge using Spatial Derivative Techniques. The algorithm of this technique operates on the pixels comprise continuous brightness value (DN value) of the pixel $(i, j)$, and this is represented as (x,y), then a vector gradient of the pixel is defined by the formula is expressed as,

$$
\nabla=\phi x, y=\frac{\partial}{\partial x} \phi x y i+\frac{\partial}{\partial y} \phi x, y j
$$

Where, $i, j$ are the pair unit of vector of the pixel $(x, y)$, in which, the direction of the vector gradient is the direction of maximum of DN values in the class and its amplitude is the value of the same class which determine the outline of objects.
The edge detection operation is used only the magnitude of the vector gradient, that is defined as,

$$
\begin{aligned}
& |\nabla|=\sqrt{\nabla_{1}^{2}+\nabla_{2}^{2}} \\
& \nabla_{1}=\frac{\partial}{\partial x} \phi x, y \text { and } \nabla_{2}=\frac{\partial}{\partial y} \phi x, y
\end{aligned}
$$

$\nabla \quad$ Where, is the magnitude gradient of pixel (x, y)

\section{Histogram Equalization}

Histogram of an image is defined as frequency of DN values against particular wave length. Histogram equalization is a nonlinear stretch that redistributes pixel values within the range. The result of the image is increased the contrast gray tone at both end of the histogram to improve the shape of the objects. Besides, the histogram equalization can separate the pixels into distinct groups from the wide range. These operations are improved the visualization of a crude classification of the objects [13]. Histogram has associated with pixels in the image that utilize the available brightness levels equally and thus can give a display in which there is good representation of objects. The formula of histogram equalization is used here. It is expressed as,

$$
h_{o} y=h_{i} x \frac{d_{x}}{d_{y}} \text { or } \frac{d_{y}}{d_{x}}=\frac{h_{i}(x)}{h_{o}(y)}
$$

Where, $h_{i}(x)$ represents the original image histogram (input image) and $\mathrm{h}_{\mathrm{o}}(\mathrm{y})$ is the histogram of the image after contrast modified. This algorithm operates to reassign the pixel values of the image to stretch the histogram from their original to the discrete interval of histogram range equally.

\section{Principal Component Analysis}

Principal Component Analysis (PCA) is provided the output image with selected features as principal components, and they are often better interpretable than the original image. PCA transformation is a method of data compression that 
allows reducing the redundant data dimensionally to be compacted into fewer bands [14]. In this study, the algorithm of PCA is correlated the set of multispectral data into two to three bands that has been more suitable for recovering the potential information from the transformed data. PCA transformation is applied to correlate IRS P6 - LISS III multispectral data with bands 2, 3, 4, and 5 into three bands. Further, the transformation is conceptualized best by considering the two-dimensional distribution of pixels in $\mathrm{x}_{1}$ and $\mathrm{x}_{2}$ axes, and the scatterplot of all the brightness value associated with each pixel located in $\mu_{1}$ and $\mu_{2}$ axes. A scatterplot shows the relationships of pixel values in two bands, and the values of one band are plotted against those of the other. A scatterplot distributed mean of data points in the axis of $\mu_{1}$ and $\mu_{2}$. At the time of execution, PCA of the image is used to translate or rotate the original axes so that the DN values on axes $x_{1}$ and $x_{2}$ are redistributed on to new set of axes or dimensions known as $\mathrm{x}_{1}$ and $\mathrm{x}_{2}$. Thus, the new coordinate system $\mathrm{x}_{1}$ and $\mathrm{x}_{2}$ were laid at the location of both mean of original data points with? Degrees so that the first axis $\mathrm{x}_{1}{ }_{1}$ is associated with the maximum amount of variance in the scatter of points to create first principal component $\left(\mathrm{PC}_{1}\right)$, and the second principal component is perpendicular to $\mathrm{PC}_{1}$ with decreasing amount of the variation in the data which is not already accounted for by previous principal components, Finally, the pixels which are accumulated on principal axis are highlighted.

\section{E. Maximum Likelihood Classifier}

The Maximum Likelihood Classifier (MLC) algorithm of supervised classification technique considers both the variances and covariance of $\mathrm{DN}$ values of the training sets based on their spectral signatures. For example, the red tone with coarse pattern along water body is defined as vegetation.
The distribution of a group of pixels in training set of particular class is characterized by the mean vector and the covariance matrix and the maximum likelihood of DN values of the pixels in a class formed in order to separate feature class. In this study, the training sets were selected for nine landform features, and the spectral signatures of each class was extracted from the area of interest GCPs that collected by GPS survey. Mathematically, the multivariate normal distribution values of training samples are applied as a key for probability density function. The likelihood algorithm is expressed as follows,

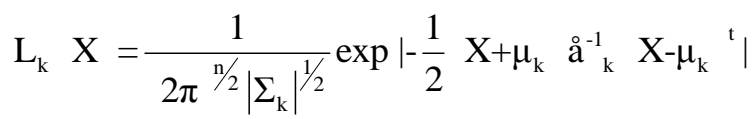

Where, $\mathrm{n}$ is number of bands, $\mathrm{x}$ refers image of $\mathrm{n}$ bands, $\mathrm{L}_{\mathrm{k}}(\mathrm{x})$ is likelihood of $\mathrm{x}$ belonging to class $\left(\mu_{\mathrm{k}}\right), \mathrm{k}$ is a mean vector of class $(\mu), \sum \mathrm{k}$ is variance-covariance matrix of class $\left(\mu_{\mathrm{k}}\right)$.

\section{RESULTS AND DISCUSSION}

\section{A. Delineation of the Shape and Linear Structure of the Feature}

The linear shape and area extent of the features have been delineated by using the edge detection algorithm. This is an optimal method to correct the errors and displacement of edge of the feature in the image due to white noise and low probability of missing true edges, and / or a low probability of false edges. The edge detection algorithm is applied to IRS P6-LISS III images to and produced output. The output image of this process is shown that the specific features with sharp edge, and they are much close to the original edge.

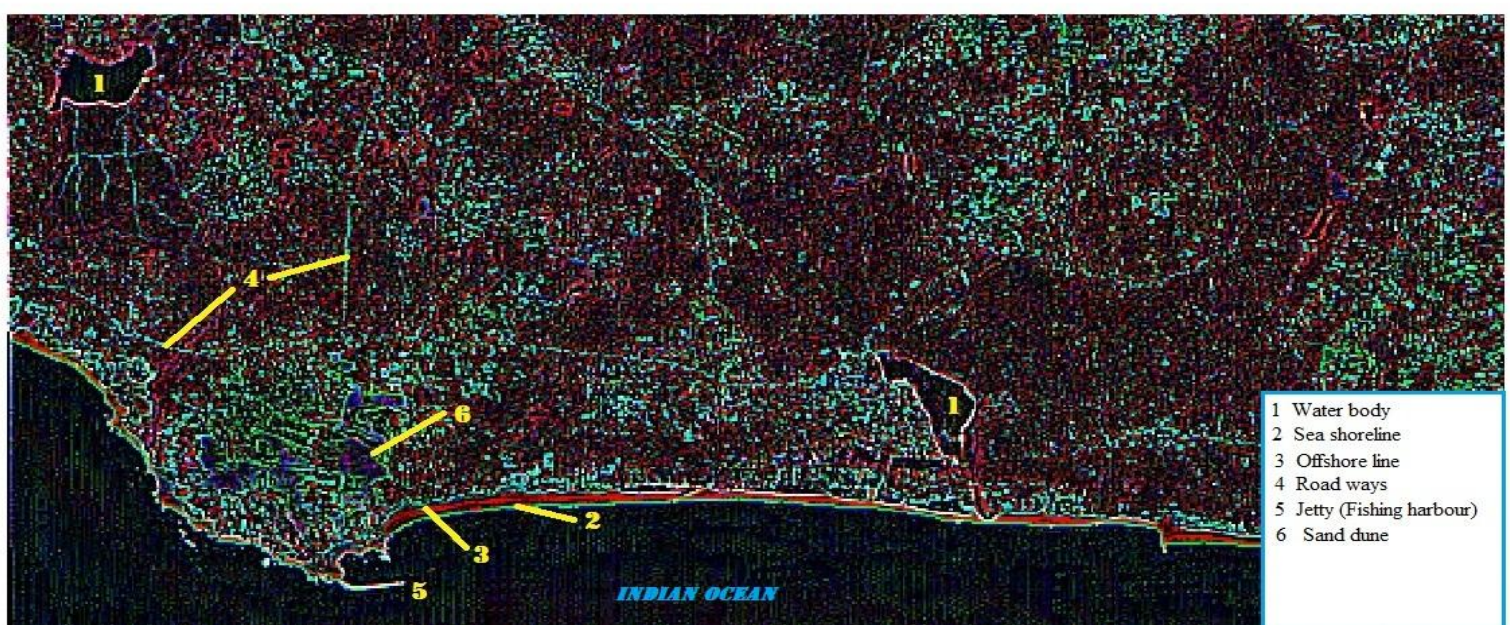

Figure 2: Feature's Linear Shape Identified by Edge Detection Process 


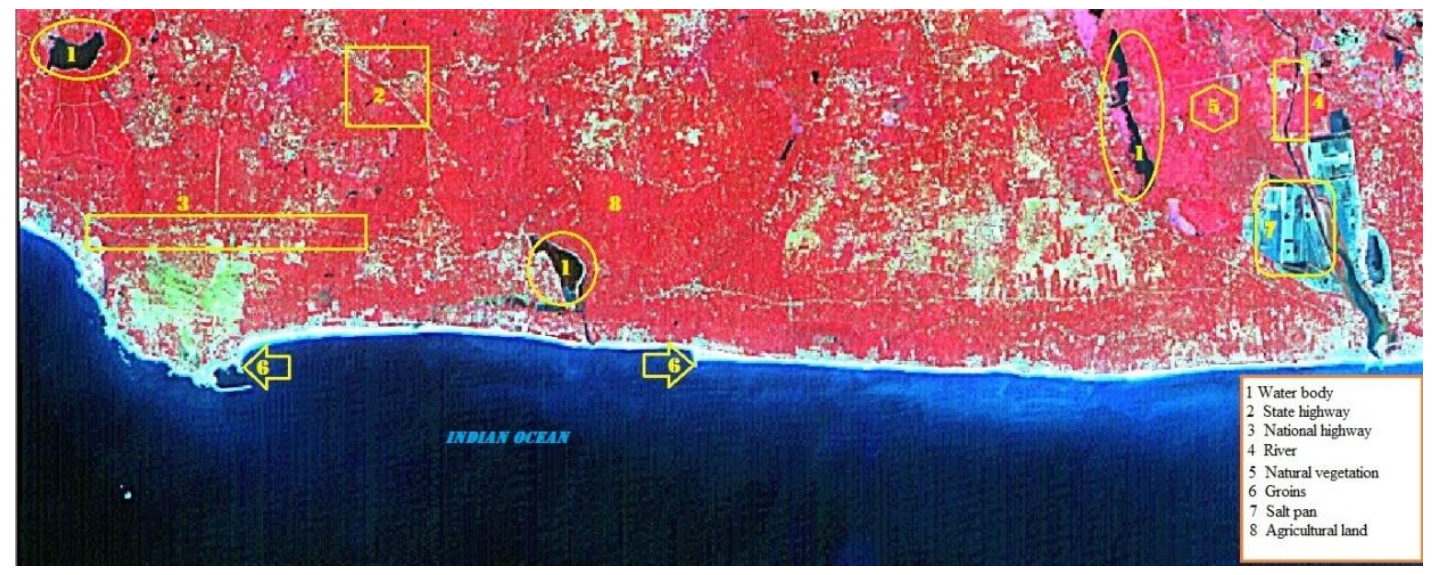

Figure3: Objects Spatial Properties using Edge Enhancement
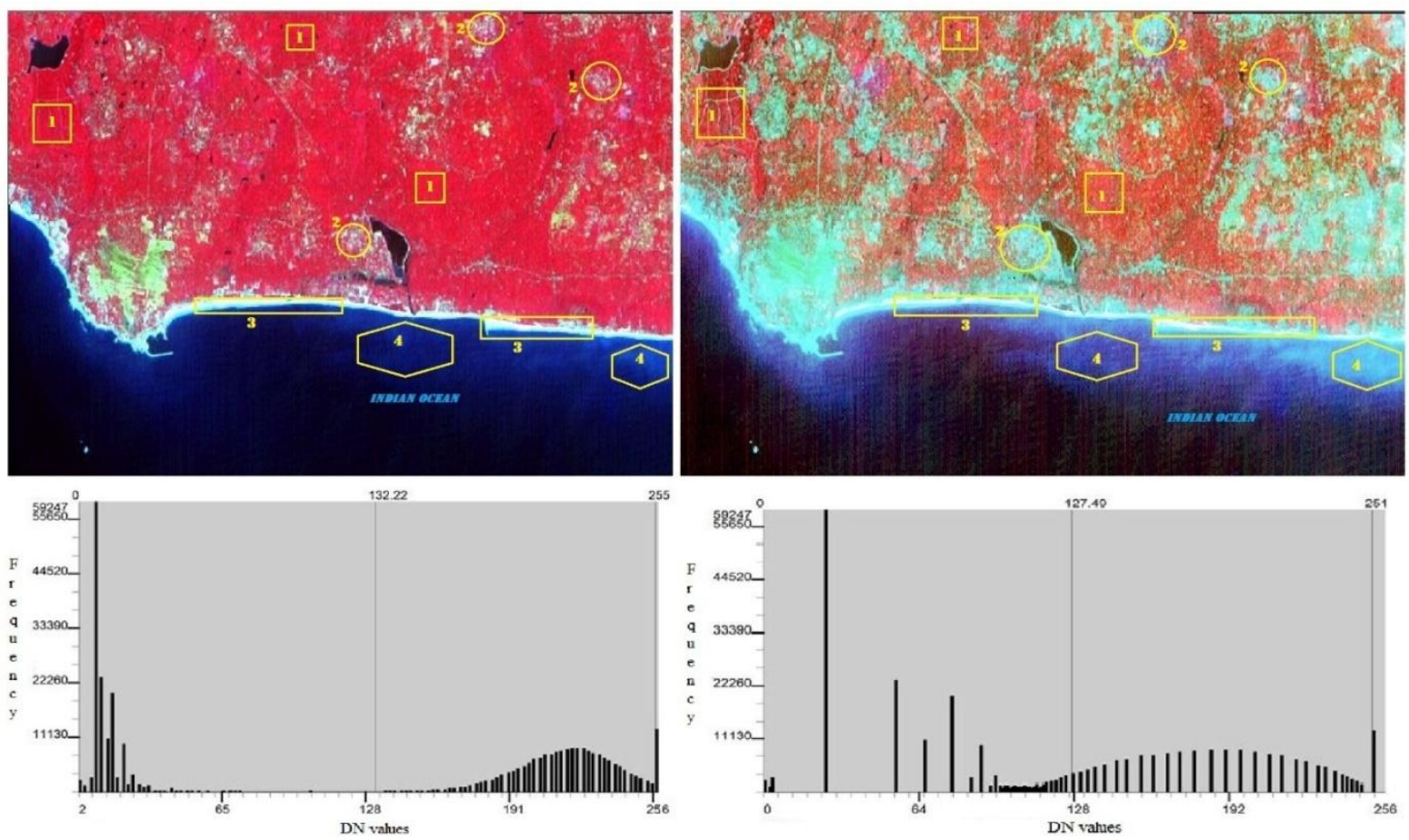

Figure 4: Delineation of Shape of the Features using Histogram Equalization

The result of image consists with light gray tone around the edge or boundary of the features, and the black and white linearly arranged pixels are highlighted the edge and shape of all linear and area features by dissolving or suppressing the brightness value of the pixels in homogenous feature (class). The pixels are laid between two contrast brightness values become highlighted to detect the edges or boundaries of the features (Fig. 2). Starting the output data, edge or boundary of the water body such as pond and lakes (1), sea shoreline (2), offshore surface (3), and manmade structures include roadways (4), and jetty or fishing Harbour (5) and Sand dune (6) are delineated with its original shape and areal extent. The figure 3 is the result of the edge enhancement process that shows the image with spectrally enhanced image. In which, the DN values of the pixels are redistributed within the brightness intensity to enhance shape and spatial location of the features. The process of edge enhancement is stretched the range of brightness intensity between dark and light gray tone of pixels in the image to highlight certain features of interest such as roadways, water bodies, shoreline and vegetative covers. The output image is used here to identify the two dimensional discrete features based on the differentiation between the edges of the adjacent features. For example, the linear features such as roadways $(2,3)$ and are features like groins (6), salt pan (7) are distinguished clearly from vegetative cover without discontinuities in their shape and extent.

\section{B. Enhancement of Location and Area Extent of Landform Features}

Histogram equalization is one of the effective image enhancement techniques for contrast enhancement. In this method, the brightness values of pixels are preserved by avoid the generation of non-existing artifacts in the output image. The original image IRS P6-LISS III images have composed by three bands (band 2-Green; band 3-Red; band 4-Near IR) with 8 bits. 
In which, each band has different stretches of the histogram. Here, band 2 has the histogram stretch between 2 to 255 , similarly The bands 3,4 have stretch ranges between 18-256 and 5-255 respectively. The combined FCC image also has narrow histogram stretch with DN value range is from 18 252 instead of $0-255$. As the result of the histogram equalized image has a wide range of DN values is from 1-255 in its histogram stretch. Besides, this process also separate the pixels into distinct groups based on their spectral similarity and enhanced specific landform features in the output image. During this analysis, the input image linearly stretched to move the least value 18 into 1 at left tail and end value 252 into 256 at the right tail of histogram plot and then all intermediate values are stretched proportionately. For example, during the first stretch, the DN values 18 to 77 moved in to DN values 1 to 67 in the output image. Consequently, the DN values 77 - 136 become $67-129$, while the DN values 136 - 195 to 129 - 191; DN values $195-$ 252 moved as 191 - 256, this process is extended the DN values into separate classes with the wide range. From the output image, the different landforms such as shrub vegetation (1), sand dunes (2), settlements (3), and the suspended sediment (4) in offshore were demarcated with their location and area extent (Fig. 4).

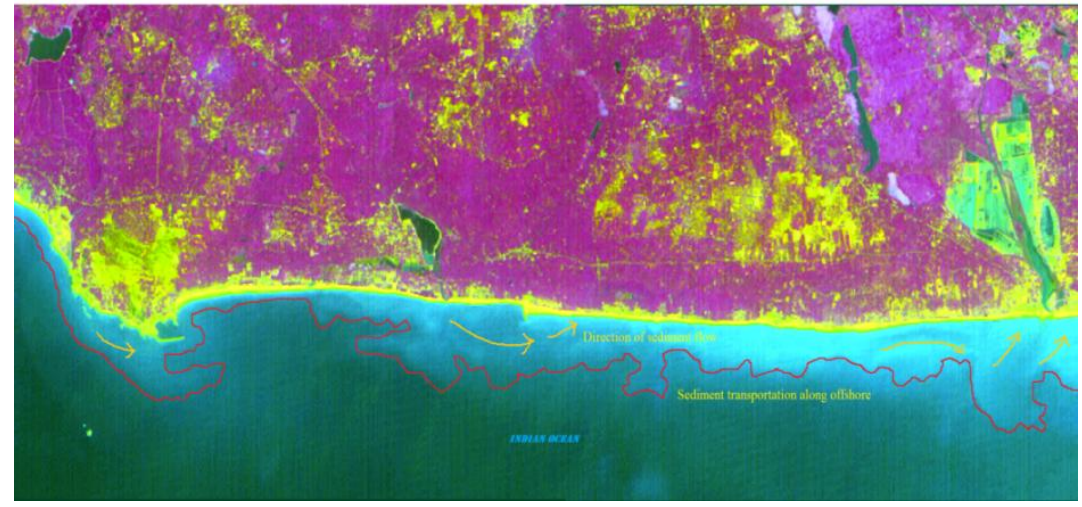

Figure 5: Assessment of Sediment Transport along Offshore using PCA Analysis

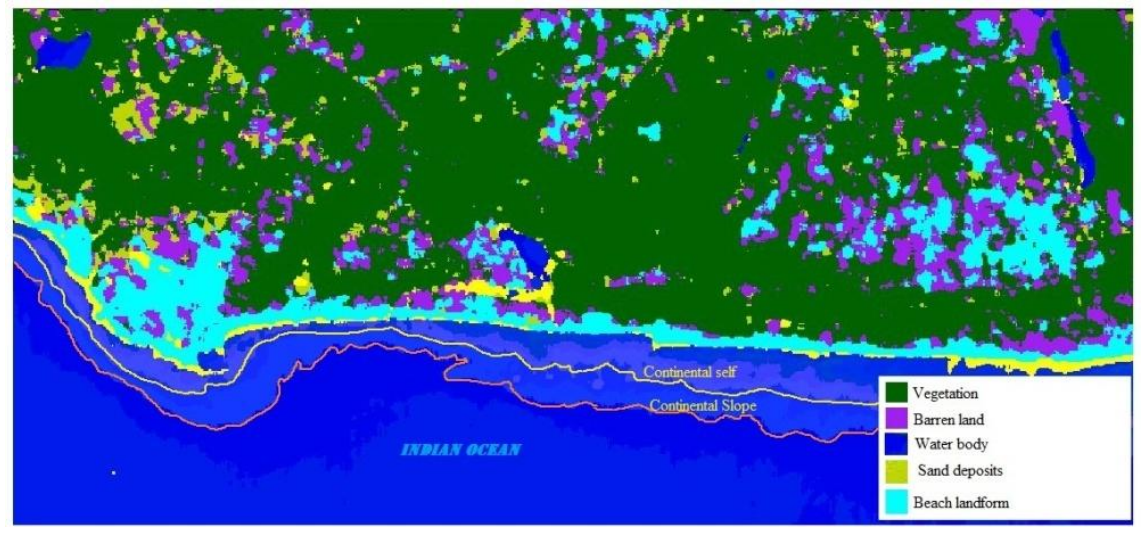

Figure 6: Coastal Landforms Extraction using MLC Algorithm of Supervised Classification

\section{Sediment Transportation Along Offshore}

The suspended particles and their movement along the offshore region were virtually extracted from IRS P6-LISS III images using PCA. This process is reduced the redundancy of pixels in all multispectral bands into three bands by correlated the pixels based on probability of homogeneous (spectral similarity) classes. The product of PCA showed the distinct gray tonal variation of the suspended materials than that of original image (Fig. 5). The PCA algorithm is applied to brightness values (DN value) of bands 2, 3, and 4 in the spectral signature plot, in which the intensity of each band is despite the moderate spectral separation between the object. During the transformation, the pixels that correspond to be offshore are plotted two dimensionally in $\mathrm{x}_{1}$ and $\mathrm{x}_{2}$ axes, and the scatter plot of all the brightness value associated with each pixel located in $\mu_{1}$ and $\mu_{2}$ axes. While the first rotation of the scatter plot, the axis is correlated the pixels of suspended materials (DN value 19-34) with the pixels of water properties (DN value 1-18) in all bands and for the separation of suspended sediment.

\section{Coastal Landform Features Extraction and Assessment}

The landforms of the study area are demarcated from the image using MLC algorithm based on supervised classification technique. In the study, the features are extracted with attributes of location, area extent and spatial distribution from IRS P6-LISS III images. In the analysis, the MLC algorithm is applied to calculate mean, variance, covariance and standard deviation of DN value in training sets to produce the cluster. Then, the clusters of individual class are applied to investigate the similar DN values in whole image and formed as separate feature classes. The result of classified image is shown that different types of landforms such as shoreline, coastal beaches, sand dunes, marshy land, water bodies, and vegetative cover. These landforms are delineated from their 
associate features based on the spectral properties of the image. For example, seashore line was identified by the cluster of DN value (215-250). Similarly; the vegetative cover has been extracted as single class by calculate the average of the different clusters of DN value (47-49; 54-59; and 65-69), this variation is due to variation in spectral properties of vegetation in the image. As well as the beach landforms are demarcated as separate class from their associated land uses such as settlement and sea surface based on tonal difference of the features (Fig. 6).

\section{CONCLUSIONS}

In the study, the coastal landform features are almost identified and demarcated from the IRS P6-LISS III images such as seashore line, coastal beaches, sand dunes, marshy land, water body, and vegetative cover. From this study, this is concluded that the statistical algorithms of image processing techniques are applied to DN values of pixels in the image to bring out the shape, size and location of landforms. The spectral and spatial properties of the pixel have significant influences in individual landforms extraction. The sea shoreline was delineated by based on DN value of pixels present in between of the offshore and onshore region. The MLC algorithm is operated on DN values of pixels in each class to determine the spectral response curve (cluster) to extract landforms such as seashore line, coastal beaches, sand dunes, marshy land, water body, and vegetative cover. From this digital image processing experimental results, this is found that the spectral properties of pixels in the image have represented shape, location and distribution of the landforms. Hence, the suitable image processing operations on the FCC image can produce the reliable results for feature extraction. Problems are faced during the practices that the coasts along the sea shore are mainly covered with beaches, sand dunes and settlements. These landforms are difficult to separate using MLC algorithm due to their spectral similarity (DN values resemblance) and this frequently cased to misclassification or overlapping. This can be solved by using high-resolution image or hyper-spectral image.

\section{ACKNOWLEDGEMENT}

The corresponding author is thankful to DST-INSPIRE Division, Department of Science \& Technology, Government of India for the award of INSPIRE Fellowship (DST/INSPIRE/2011/IF110366) for pursuing the Ph.D Degree programme.

\section{REFERENCES}

[1] C. Sheffield, "Selecting band combinations from multi-spectral data," Photogrammetric Engg and Remote Sensing, Vol. 5, Pp. 681-687, 1984.

[2] J.A. Richards, Xiuping Jia, "Remote Sensing Digital Image Analysis," Springer Publication Vol. 3, Pp. 227-249, 1998.

[3] R.N. Colwell, "From Photographic Interpretation to Remote sensing," Photogrammetric Engineering and Remote sensing, Vol. 50, Pp. 13051307, 1984.

[4] G.H. Suits, "The Nature of Electromagnetic Radiation in the manual of Remote sensing," American Society of Photogrammetry and Remote sensing, Vol. 1(50), Pp. 1305-1307, 1984.

[5] R.N. Swain, S.M. Davis, "Remote sensing: The Quantitative approach," $2^{\text {nd }}$ ed., Pp. 105-130, 1978.
[6] S. Ustin, "Remote sensing for natural resource management and environmental monitoring: Manual of remote sensing," John Wiley and Sons, NJ, USA, Pp. 223-225, 2004.

[7] S. Kaliraj, S. Muthu Meenakshi, V.K. Malar, "Application of Remote Sensing in detection of Forest cover changes using Geo-Statistical change detection matrices - A Case Study of Devanampatti Reserve Forest, Tamilnadu, India," Nature Environment and Pollution Technology, Vol. 11(2), Pp. 261-269, 2012.

[8] J. Gower, "Remote sensing of the marine environment: Manual of remote sensing," The American Society for Photo grammetry and Remote Sensing, Bethesda, Maryland, USA, Pp. 624-642, 2006.

[9] Q. Zhang, J. Wang, X. Peng, P. Gong, P. Shi, "Urban built-up land change detection with road density and spectral information from multitemporal Landsat TM data," International Journal of Remote Sensing, Vol. 23(15), Pp. 3057- 3078, 2002.

[10] Yanbo Huang, Guy Fipps, E.L. Ronald, J.T. Steven, "Landsat Satellite Multi-Spectral Image Classification of Land Cover and Land Use Changes for GIS-Based Urbanization Analysis in Irrigation Districts of Lower Rio Grande Valley of Texas," Applied Remote sensing Journal, Vol. 2(1), Pp. 27-36, 2011

[11] Habti Abeida, Xianqi Li, Jian Li, Mosleh, M. Al-Harthi, "Iterative Sparse Maximum Likelihood-based Algorithms with Applications to SAR imaging" Int Journal of Remote sensing Applications, Vol. 2(2), Pp. 10-23, 2012.

[12] R.G. Congalton, K. Green, "Assessing the accuracy of remotely sensed data: principles and practices," Lewis Publishers, Inc, Boca Raton, Florida, USA, Pp. 25-28, 1998.

[13] J.R. Jensen, D.L. Toll, "Detecting Residential Land use Development at the Urban Fringe," Photogrammetric Engineering and Remote sensing, Vol. 50, Pp. 526, 1982.

[14] R.M. Haralick, Fu. "Glossary and Index to Remotely sensing image pattern recognition concepts," Pattern Recognition, Vol. 5, Pp. 391-403, 1983.

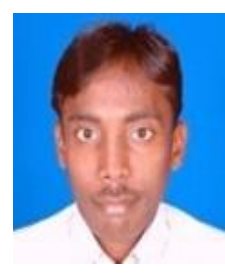

S. Kaliraj is a DST-INSPIRE Fellow. Presently, He is pursuing Ph.D degree in Remote sensing in Centre for GeoTechnology, Manonmaniam Sundaranar University. He has received the B.Sc. degree in Biology from St.Xavier's College, Palayamkottai, Tirunelveli, Tamilnadu, India in 2006 and M.Sc in Environmental Remote sensing and Geo Information Technology with University First Rank from Department of Remote sensing and Cartography, Madurai Kamaraj University, Madurai, India in 2008. He has completed M.Tech - Geomatics professional course from Indian Institute of Surveying and Mapping, Survey of India, Uppal, Hyderabad, India in 2011. He has one year teaching experience in Remote sensing and GIS modeling subjects. His research interests are in the areas of Remote sensing, GIS, Digital image processing, Surveying and Mapping and Natural resource management. He has also presented and published significant number of research papers in international seminars and journals

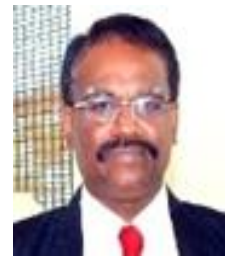

Prof. Dr. N. Chandrasekar received his Post Graduate degree in Marine Geology from CUSAT, Kochi and $\mathrm{Ph} . \mathrm{D}$ degree in Marine Mineral Exploration from Madurai Kamaraj University, Madurai. Currently he is Professor and Head, Centre for GeoTechnology, Manonmaniam Sundaranar University, Tirunelveli, India. His research interests are Remote sensing and GIS application in Coastal geomorphology and Geo Marine Technology. He has guided more than 22 students for Ph.D degree. He has published more than 150 refereed research papers in International and National journals. He also reviewed various International and National Journals like Indian Journal of Geomorphology, Geosciences Frontiers (Springer), Current Sciences, International Journal of Remote sensing (Taylor \& Francis), International Journal of Environment \& Eco-planning. He is a member of various professional International/National bodies and government organizations. He is the recipient of Prof. E.P. Odum Gold medal and M.S. University Academic Excellence Award - 2009. 